Portland State University

PDXScholar

World Languages and Literatures Faculty

Publications and Presentations

9-26-2012

\title{
The Semiotic Ecology and Linguistic Complexity of an Online Game World
}

\author{
Steven L. Thorne \\ Portland State University \\ Ingrid Fischer \\ University of Groningen \\ Xiaofei Lu \\ Pennsylvania State University
}

Follow this and additional works at: https://pdxscholar.library.pdx.edu/wll_fac

Part of the First and Second Language Acquisition Commons, Language Description and

Documentation Commons, Semantics and Pragmatics Commons, and the Typological Linguistics and

Linguistic Diversity Commons

Let us know how access to this document benefits you.

\section{Citation Details}

Steven L. Thorne, Ingrid Fischer and Xiaofei Lu (2012). The semiotic ecology and linguistic complexity of an online game world. ReCALL, pp 279301

This Article is brought to you for free and open access. It has been accepted for inclusion in World Languages and Literatures Faculty Publications and Presentations by an authorized administrator of PDXScholar. Please contact us if we can make this document more accessible: pdxscholar@pdx.edu. 


\section{ReCALL}

http://journals.cambridge.org/REC

Additional services for $\operatorname{Re} C A L L$ :

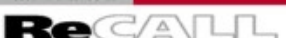

Additional services for ReCALL:

Email alerts: Click here

Subscriptions: Click here

Commercial reprints: $\underline{\text { Click here }}$

Terms of use : $\underline{\text { Click here }}$

\section{The semiotic ecology and linguistic complexity of an online game world}

Steven L. Thorne, Ingrid Fischer and Xiaofei Lu

ReCALL / Volume null / Issue 03 / September 2012, pp 279 - 301

DOI: 10.1017/S0958344012000158, Published online: 26 September 2012

Link to this article: http://journals.cambridge.org/abstract_S0958344012000158

How to cite this article:

Steven L. Thorne, Ingrid Fischer and Xiaofei Lu (2012). The semiotic ecology and linguistic complexity of an online game world. ReCALL, null, pp 279-301 doi:10.1017/S0958344012000158

Request Permissions : $\underline{\text { Click here }}$ 


\title{
The semiotic ecology and linguistic complexity of an online game world
}

\author{
STEVEN L. THORNE \\ Portland State University (USA) and University of Groningen (Netherlands) \\ (email: steven.thorne@pdx.edu) \\ INGRID FISCHER \\ University of Groningen, The Netherlands \\ XIAOFEI LU \\ The Pennsylvania State University, USA
}

\begin{abstract}
Multiplayer online games form complex semiotic ecologies that include game-generated texts, player-to-player communication and collaboration, and associated websites that support in-game play. This article describes an exploratory study of the massively multiplayer online game (MMO) World of Warcraft $(W o W)$, with specific attention to its qualities as a setting for second language (L2) use and development. This empirical study seeks to answer the following question: What is the nature of the linguistic ecology that $W o W$ players are exposed to? Many studies have described the developmental opportunities presented by commercially available gaming environments (e.g., Gee, 2003, 2007), their value as sites of literacy development (e.g., Squire, 2008a; Steinkuehler, 2008), and their potential as venues for second language (L2) use and learning (e.g., Peterson, 2010; Thorne, Black, \& Sykes, 2009; Thorne \& Fischer, 2012; Zheng, Young, Wagner \& Brewer, 2009). There are, however, numerous outstanding questions regarding the quality and complexity of the linguistic environments associated with online commercially available games. This primarily descriptive research addresses this issue and aims to finely characterize the linguistic complexity of game-presented texts (or 'quest texts') as well as player generated game-external informational and strategy websites that form the expansive semiotic ecology of $W o W$ game play. Questionnaires and interviews with Dutch and American gamers helped to identify a variety of widely used game-external websites. This information then informed the selection of texts that were analyzed for their linguistic complexity. By analysing the linguistic complexity of the texts that players regularly engage with, this study aims to empirically assess the resources and limitations of a representative and widely played MMO as an environment for L2 development.
\end{abstract}

Keywords: linguistic complexity, massively multiplayer online games, second language development, semiotic ecology

\section{Introduction}

Online gaming is a powerful force in contemporary popular culture. In addition to their mercurial rise in popularity and position as one of the most complex forms of 
media-based entertainment, digital game-based environments are also being used in contexts such as children's museums, scenario-based management and military training, and increasingly, for instructional purposes in a range of science and humanities subjects. The expanding applications for digital games have been accompanied by a rapid diversification of the types and genres of games being developed (see Purushotma, Thorne \& Wheatley, 2009; Sykes, Reinhardt, \& Thorne, 2010).

More broadly, the use of games as environments for exploration, simulation, and experiential learning is provoking a shift from models of education based on information delivery and toward theories of human development that emphasize designed experiences, the negotiation of social and situational scenarios, and complex forms of collaboration (Squire, 2008b). Recent research has also suggested that complex multiplayer video game cultures foster workplace attributes such as the use of feedback for continual improvement, understanding the power of diverse teams, the ability to cope with (and enjoy) rapid change and unpredictability, and seeing learning as a process of assembling human and material resources to overcome obstacles. Brown and Thomas (2008) described this constellation of qualities 'the gamer disposition.'

In consideration of the postulated merits of video games, attempts have been made to develop educational video games that specifically cater to certain learning objectives. However, as Gee (2003), Lee and Hoadley (2007) and Nardi, Ly and Harris (2007) argued, these efforts are often only marginally successful in part because 'play' is replaced. by repetitive and superficial tasks in which the learning objectives are too obvious. Developing video games that are both of commercial grade quality and explicitly educational is difficult and expensive, thus a logical step is to closely examine existing commercial video games as potential sites for second language (L2) use and development.

Most theories of adult L2 development, to a greater or lesser degree, acknowledge the importance of meaningful communicative engagement and exposure to adequate volumes of the L2 so that its distributions, frequencies, functions, and forms become salient and learnable (e.g., Ellis \& Collins, 2009; Ellis \& Ferreira-Junior, 2009). In combination with social, affective, and cognitive dynamics, quantity of exposure/ engagement and quality of the linguistic environment are primary drivers of language development. ${ }^{1}$ With respect to L2 learning and online games, however, there are many unanswered questions regarding the quality and complexity of these linguistic environments, especially those associated with 'non-educational' off-the-shelf recreational games. To our knowledge, this is the first study that methodically surveys players of massively multiplayer online games (hereafter MMOs) to ascertain which

1 In an empirical demonstration of the importance and relevance of frequency and quality of input in first language acquisition, Hart \& Risley (1995) report that by the age of four, American children raised in highly educated professional families have been exposed to approximately 20 million more words than children in working class families and 35 million more than children whose families qualify for welfare services. The effect on vocabulary development was enormous, with professional class children measured as having twice the vocabulary of children raised in families on welfare. This research starkly underscores the relevance of linguistic (and likely material) conditions to trajectories of development. 
texts they attend to while playing, and subsequently, to submit these various texts to careful linguistic analysis in an attempt to ascertain their complexity. For L2 educators, as well as scholars interested in linguistic analysis of new media texts, the hope is that this research will provide an empirical basis for consideration of online games as sites for language learning and further will contribute to better understanding the cognitive and linguistic complexity of these settings.

The research comprising this article is part of a larger project that investigates the multiple and interrelated discourses and communicative dynamics that constitute routine play in MMOs. To be clear, this study does not report on L2 learning directly, rather, the goal of the descriptive research presented here is to formally and objectively assess the linguistic complexity of game-presented texts (or 'quest texts', the tasks that are given to players which structure their activity in the game) as well as game-external websites that are widely used by, and generally produced by, active gamers. In a second companion article, reports of gamers' preferences, play styles, and language learning experiences are addressed (see Thorne \& Fischer, 2012). The MMO chosen for analysis is World of Warcraft (hereafter WoW), currently the most popular of the burgeoning number of available multiplayer games, with a player base of more than twelve million people.

\section{Background research and introduction to the study}

\subsection{Cognitive and social-psychological affordances of (online) gaming worlds}

There has been considerable research on the structure, organization, and forms of social practice that play out in MMOs, and particularly WoW (e.g., Gee, 2003; Grimes \& Feenberg, 2009; Nardi \& Kallinikos, 2010; Steinkuehler \& Duncan, 2008; Thomas $\&$ Brown, 2009). These studies have uniformly assessed $W o W$ and other MMOs as developmentally rich environments for the learning of literacy, scientific reasoning, problem solving, leadership, and collaboration. Aspects of game world design have also been argued to be relevant to rethinking educational cultures and environments, for instance the fact that players of differing ability levels share a common space and frequently interact with one another. In most game worlds, knowledge is freely shared because everyone benefits when there are better players to collaborate with, and over time, all players have the prospect of progressing to higher levels of accomplishment. Gee (2005) has described such dynamics using the term "affinity spaces" and has argued that formal education could well be improved by adopting the pedagogical and developmental cultures that are common to multiplayer online games.

It is relevant to note that other commentators and researchers have expressed more negative views of cognitive (e.g., Carr, 2010) and social-psychological (Turkle, 2011) processes that pertain to Internet environments as well as to single and multiplayer online games. In regard to social media, for example, Turkle, who in the 1990s positively assessed the many identity construction opportunities in Internet-based virtual and gaming environments (e.g., Turkle, 1995), has more recently condemned social media, arguing that immersion in the cacophony of social media networks and 'friendships' may result in a sense of increased isolation (Turkle, 2011; though see Steinfield, Ellison \& Lampe, 2008, for a longitudinal study that suggests an opposite effect). In relation to 
L2 learning and video games, deHaan (2005) reviewed several single player and console based game genres and concluded that they were limited as environments for L2 learning. deHaan specifically faulted such games for their contrived and genrelimited language content (sports and 'virtual pet' games), the relative irrelevance of language to game play (simulation games), and in games that are language-intensive, for instance those in the role playing and action adventure genres, that the gaming environment does not allow learners to revisit, pause, or otherwise moderate the highly complex narratives and linguistic input in a way that would assist with comprehension and L2 development, especially for lower level language learners (though see Piirainen-Marsh \& Taino, 2009, for a contrary assessment). Given the large volume of time that many gamers spend in MMO settings, the criticism that online activity displaces (arguably) more meaningful face-to-face engagement, or presents learners with 'inauthentic' or overly complex language, are important issues that warrant continued exploration (for further discussion, see Thorne \& Fischer, 2012).

In other research within the L2 literature, Peterson (2010) produced a meta-analysis of L2 research on gaming that outlined a number of positive attributes, among them high motivation, the need and opportunity for collaboration, and reduced that communicative inhibition. In a study examining an intercultural encounter in $W_{o} W$, Thorne (2008) analysed the transcripts of text-chat communication between an American and a Ukrainian player. His analysis illustrated a number of positive assets for language learning, such as natural and unscripted interaction, reciprocal alterations in expert status, explicit self- and other-correction at the level of linguistic form, extensive repair sequences, development of a positive affective bond, and exhibited motivation by both parties for learning the other's language. While existing research describes the considerable potential of MMOs as sites for L2 learning (e.g., Reinders, 2012; Sykes et al., 2010), there remains an outstanding need for meticulous empirical studies that critically evaluate the environments games provide for L2 learning.

\subsection{The Anatomy of an MMO: World of Warcraft}

As described above, $W_{o} W$ is a commercial massively multiplayer game, produced by Blizzard Entertainment, within which thousands of people simultaneously engage in solo play, collaborative play, match competitions and duels, commercial activity (making, buying, and selling items in an in-game economy), and participation in social interaction more generally. Game play involves controlling a digital avatar within a 3-D virtual world and completing game-generated "quests" or goal-oriented tasks to advance one's character to higher levels. As will be further described below, quests are presented to players as pop-up text windows that are approximately 100 words in length. In-game communication includes a variety of synchronous chat channels, an asynchronous email system, and a number of voice-communication tools that enable audio communication between players. Players also frequent gameexternal websites for advice regarding character development, for assessing the relative value of various items in the game (e.g., armor and weapons), to glean strategy for completing individual quests and more challenging group play (called instance runs and raids), and to pursue interests in the narrative, lore, and popular culture outgrowths of the game (e.g., machinima, fan fiction). 


\subsection{Global objective and procedures for the study}

The study presented here includes questionnaires, completed by 64 gamers in total, and follow-up oral interviews with ten of the respondents. The responses provided by these players helped to identify and inform the selection of texts that were analysed for their linguistic complexity. By analysing the linguistic complexity of the texts that $W o W$ players frequently engage with, this study aims to empirically document the quality of the linguistic ecology comprising a representative and widely played MMO, and to then describe its affordances and limitations in view of L2 development.

\section{Selection of in- and out-of-game texts for linguistic analysis}

\subsection{Method: Bi-national questionnaire and interviews with WoW players}

In order to establish the routine practices and experiences of $W o W$ gamers, in the Spring of 2011, the authors created a questionnaire instrument. The questionnaire was targeted toward Dutch players living in the Netherlands, for whom English was an L2, and American players living in the United States, in order to gain an international perspective of $W o W$ gaming experience. The questionnaire consisted of 40 questions, beginning with demographics and background (e.g., age, gender, education, nationality); frequency of play; use of external websites and resources; the nature of their specific $W o W$ experience including the official language of the realm they play on, membership within guilds (akin to structured clubs or teams) and the balance of solo to collaborative play; patterns of socializing and communication, and preferred communication tools. These topics were then further explored through self-selected and voluntary follow-up interviews with ten of the questionnaire respondents. These interviews were carried out via video conferencing (Skype), and in one instance, in a face-to-face format.

Only a subset of the questionnaire and interview data will be addressed here, namely the ways that players described interacting with quest texts and their use of websites that are external to the game (for analyses and discussion of other aspects of this project, see Thorne \& Fischer, 2012). ${ }^{2}$ As a caveat, we acknowledge that questionnaire data have the potential to be inaccurate, but numerous studies have also found high levels of congruency between self-reported data and objective assessments (e.g., Crockett, Schulenberg, \& Petersen, 1987). Additionally, responses to the questionnaire regarding the focal themes explored here, namely the reading of quest texts and the use of external websites, were highly consistent across the bi-national sample of respondents. An additional 'in-group member check' is possible since two of the authors (Thorne and Fischer) have collectively played $W o W$ for hundreds of hours, including attaining the maximum level caps for two earlier iterations of the game, and our play experiences allow us to further corroborate the validity of the questionnaire results.

2 The specific questionnaire item was: "Do you use any external sites that have to do with $W o W$ (i.e. online information, strategy sites, forums)? Please list which ones, for what purpose, and in what language." In each of the ten follow-up interviews with self-selected players, this question was further investigated (see section 3.6 for the relevant discussion). 


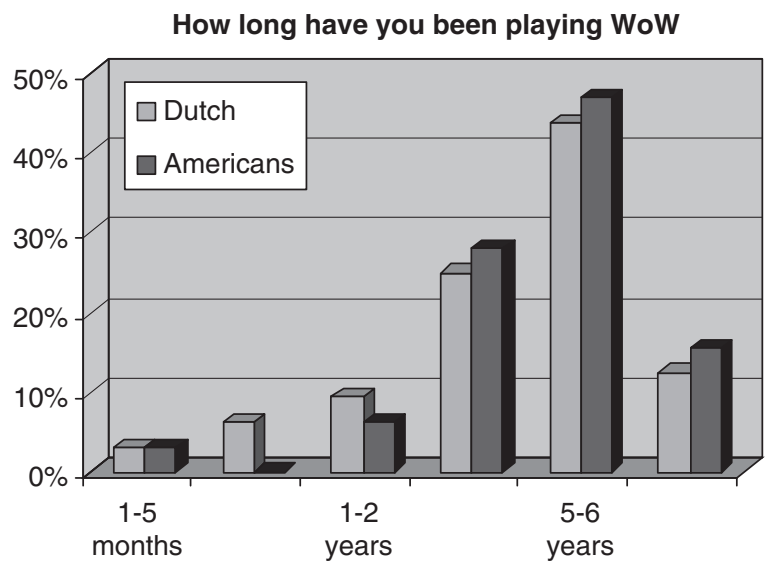

Fig. 1. Length of time Dutch and American participants have been playing $\mathrm{WoW}^{\mathrm{W}}$

\subsection{Demographic profile of the questionnaire respondents}

Dutch and English versions of the questionnaire were made available and it was distributed through various social networks (including the WoW Facebook page), emailed directly to Dutch and American players known by the authors, and posted to online $W_{o} W$ community websites with the encouragement for initial respondents to redistribute the questionnaire to other players. There was an equal number of Dutch $(\mathrm{N}=32,16$ females, 16 males) and American $(\mathrm{N}=32,11$ females, 21 males $)$ respondents. On average, the Dutch participants were younger $(\mathrm{M}=26.6, \mathrm{SD}=8.9)$ than the Americans $(\mathrm{M}=33.1, \mathrm{SD}=9.2)$. None of the questionnaire respondents were playing WoW specifically to learn a foreign language, but all of the Dutch and American participants reported playing on English language realms. The respondents from the Netherlands all indicated that Dutch was their L1 and that they had learned English as an L2. 93\% of the Dutch players indicated that they spoke English at an advanced level. In contrast, 31 of the 32 Americans were playing in their L1 of English.

\subsection{Game play experience}

The Dutch and American groups were equally, and generally highly, experienced in playing MMOs. On a scale of 1-5 for experience, the Dutch had an average score of $4.3(\mathrm{SD}=.99)$ and the American participants an average score of $4.6(\mathrm{SD}=.71)$. An independent samples t-test showed no significant difference between the two groups $(\mathrm{t}(62)=-1.3 ; \mathrm{p}>.05)$. In both groups, most participants had been playing for more than three years (Figure 1), between one and four times a week (Figure 2), for an average of three hours at a time (Figure 3).

\subsection{Identification and use of external WoW-related websites and resources}

In both the Dutch and American questionnaire and interview groups, all respondents reported that they often used external websites relating to $W_{o} W$. The results demonstrate that $W o W$ players looked up information on how to find certain items, 


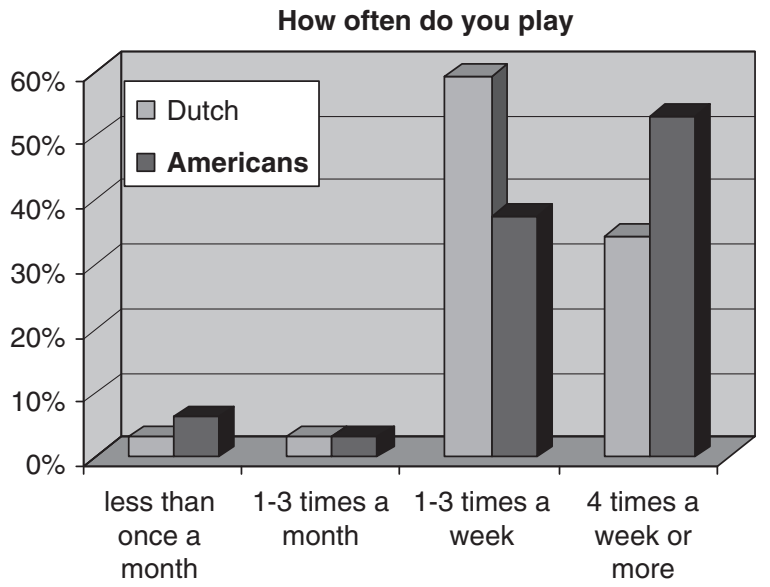

Fig. 2. Frequency with which Dutch and American participants have been playing $W o W$

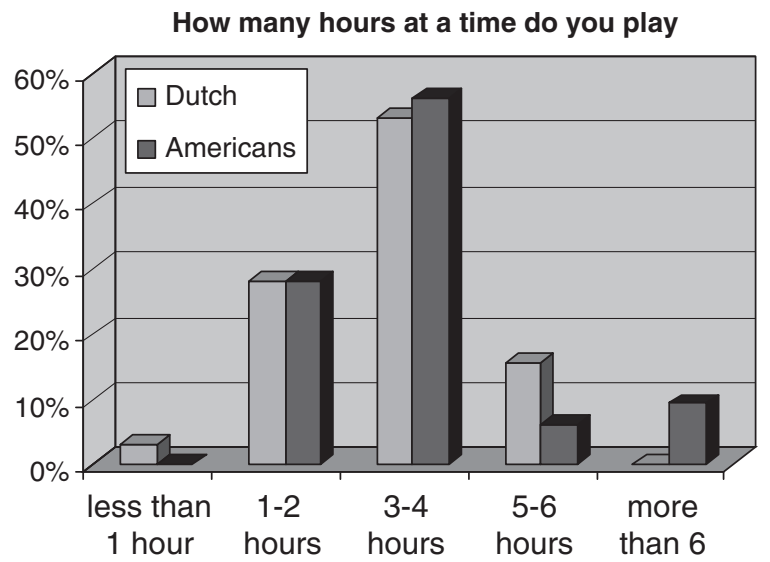

Fig. 3. Number of hours Dutch and American participants play $W o W$ at a time

how to complete quests, information on the different player classes, strategy issues, and sites related to $W o W$ lore and mythology, to name only the most frequently mentioned reasons.

Three websites were designated as the most frequently visited. The first was wowhead.com, used to look up quest strategy and information about items such as armor and weaponry. Second was wowwiki.com, which serves as a repository for $W_{o} W$ lore, background and history. The third most frequently used site was elitistjerks.com, visited mainly for information regarding game strategy. These sites were reported to have been accessed in English by all respondents, both Dutch and American. This is worth mentioning since $W o W$-related websites and online communities exist in many languages. For example, wowwiki.com is available in 26 different languages, including Dutch, and wowhead.com is available in German, English, Spanish, French and Russian. Despite the possibility of looking up information in many different languages, all participants reported using only the English versions. 


\subsection{Quest texts: Are they important to read?}

The ten self-selected $W o W$ players who agreed to be interviewed as part of this project were asked to discuss the importance of reading quest texts and, in the sub-section below, how and when they used external websites. Changes to the WoW interface to accommodate what are sometimes referred to as 'casual gamers' include enhanced map features, enhanced tracking, and spatial location assistance. This has made determining the purpose and location of the quest elements less reliant on close reading of the quest texts themselves. However, as the interviewees report below, quest texts remain an omnipresent and important source of information in the game. Note that all names are pseudonyms created using the name generating function within $W o W$.

Gláwen:

"Sometimes I get stuck on a quest, even with those huge helping functions they've incorporated now. ... So normally I actually hardly read the quest texts, only the top and the bottom part. It is only when problems arise, when I am somewhere and I cannot figure it out, then I start reading the text, because then it has information I apparently needed to know." [translated from Dutch]

Glakela:

"Sometimes you just read too quickly, and then you end up endlessly looking for something. This happened to me yesterday, and I had just not read the quest text well enough. It turns out I forgot to read one line in the quest text and I was supposed to be one floor up. So yeah, it is most definitely important to read your quests well." [translated from Dutch]

\subsection{Importance of external websites}

The importance of external websites was underscored by the all interviewees, with each reporting that they used external websites before, during, or after the gaming sessions. For this reason, we propose that external websites are an integral part of the Wo $W$ gaming experience. This observation is borne out in the following transcribed portions of the interviews.

Toclya:

“I really don't like to search for things. So if there is a mob boss that I can't find after like an hour I'm like I am done, I don't wanna search for this anymore. ... And so either my husband would search for it and then come get me or we'd just look it up. Usually we would look it up either on my I-phone, or just go back and forth between two windows for sure. Yeah I would basically just type in the quest title and then it would come up. Whatever I found to be sort of the best one is the one that I would use."

Moonpunisher:

"I use quite a few external websites, and I have all of them open while I am playing the game, so that when I need to I can immediately look stuff up." [translated from Dutch] 


\section{Glakela:}

"I never play full screen, I always play in a way so that I can just reach my desktop and can immediately access my browser. I will just put myself in a safe town, so nothing can happen and then I will calmly start reading and looking up things." [translated from Dutch]

Based on the interviews it became clear that using external websites was not only a preparatory or post hoc evaluative process, but also an integral part of the momentby-moment gaming experience.

\section{Linguistic complexity analyses}

In the prior section, players described what semiotic resources they attended to and utilized with greatest frequency. Acknowledging the critical importance of the quality of the linguistic environment as a necessary, if also by itself insufficient, contributor to language development, the question asked here is, what is the linguistic nature of these texts? The following section describes in considerable detail the linguistic complexity of the texts that were designated as highly important to playing the game.

\subsection{Method and rationale}

A key use of basic research on text analysis is its application to the operationalization and measurement of linguistic complexity. Of course, experienced educators and MMO players know intuitively that some texts are more difficult than others, but the goal of this research is to accurately and objectively assess the complexity of texts that gamers most frequently engage with.

Linguistic complexity can be broadly defined as the range and sophistication of language forms and structures (e.g., Ortega, 2003). Precise measurement of linguistic complexity has proven challenging and numerous algorithms have been developed. In this research, we assess the readability, lexical sophistication, lexical diversity, and syntactic complexity of the texts using four indices that have been shown in previous research to be useful measures of linguistic complexity. As will become clear in the discussion, these measures come with certain limitations, particularly as a result of conflating sentential variability to mean scores, but each also provides a useful vantage point from which to analyze and describe complexity.

\subsection{The linguistic complexity measures}

A number of readability formulas are used for gauging or designing the grade level appropriateness of reading materials. Criticism has been levelled at the use of readability formulas in that they tend to focus on character, word and/or sentence length as a proxy for actual lexical or structural analysis (e.g., Davison \& Kantor, 1982). However, we are including one readability measure here, the Coleman-Liau Index (CLI) (Coleman \& Liau, 1975), as it is a valued representative of the many 
Table 1 Overview of the measures chosen to determine the linguistic complexity of the text samples under investigation

Measures of linguistic complexity

Factor

Measure and acronym

Readability

Coleman-Liau Index (CLI)

Lexical sophistication

Lexical Sophistication (LS)

Lexical diversity

Syntactic complexity

Mean Segmental Type-Token Ratio (MSTTR)

Developmental-Level scale (D-Level)

readability measures available. The CLI numeric output correlates with predicted grade level reading abilities based on the American educational system (e.g., a numeric score of 7.0 would indicate a $7^{\text {th }}$ grade reading level, appropriate for twelve-to- fourteen-year-olds). The formula to calculate CLI, in which C, W, and $\mathrm{S}$ stand for the total number of characters, words and sentences respectively, is: $5.89 * \mathrm{C} / \mathrm{W}-30 * \mathrm{~S} / \mathrm{W}-15.8$.

To determine lexical sophistication (LS), the proportion of sophisticated words in a text is measured. For analysis of the $W o W$ corpora, we adopt a frequency-based approach and consider a word sophisticated if it is not on the list of the 2,000 most frequent words in the American National Corpus (ANC; see Reppen \& Ide, 2004). The specific measure used here is the ratio of sophisticated lexical word types, calculated as the number of sophisticated lexical word types divided by the number of lexical word types. Following $\mathrm{Lu}$ (in press), we define lexical words as nouns, adjectives, verbs (excluding modal and auxiliary verbs), and adverbs with an adjectival base.

The measure used for lexical diversity is the Mean Segmental Type-Token Ratio (MSTTR) (Johnson, 1944). Lexical diversity measures the range of vocabulary displayed in a text. Type-token ratio, which stands for the ratio of word types to word tokens, is a widely used measure for lexical diversity, but has been shown to decrease as the length of a text increases. The use of MSTTR corrects for this problem. MSTTR is calculated by dividing the text into segments of 50 words and then calculating the average TTR for each segment.

Syntactic complexity is here measured using the Developmental Level (D-Level) scale (Covington, He, Brown, Naçi \& Brown, 2006; Lu, 2009; Rosenberg \& Abbeduto, 1987). This measure uses sentences as a unit of analysis and then assigns individual sentences to one of eight developmental levels that ascend in complexity from 0 to 7 . The D-Level scale was developed using child language acquisition research and has been positively evaluated in application to both written and spoken data (e.g., the CHILDES database, see MacWhinney, 2000). The D-Level scale aims to measure syntactic and structural complexity, and not merely proxy measures such as sentence length or word length. Examples of different D-Level sentence types that come from our text samples, accompanied by linguistic annotation, are presented below (see Table 6). 


\section{Linguistic complexity analysis of in-game text samples: Quest texts}

\subsection{Description of corpora}

Within the game itself, a primary source of game-generated language is in the form of quest texts. Quests guide players through the game and provide instructions for carrying out specific tasks. There are currently more than 9,500 quests in $W o W$ and most involve finding resources, vanquishing foes, transporting messages or goods, and exploration. Quest texts are typically presented to a player by a non-player character (or NPC, which refers to non-human computer-generated in-game characters). Upon completion of a quest, the player receives rewards that include gold (the currency in $\left.W_{o} W\right)$, useful items, reputation, and/or experience points.

To insure that the quest text samples are representative and likely to have been seen by most players, two separate corpora were assembled, one comprising quest chains and a second built from quests that are specific to one of the ten different classes (or character types) that can be played. The rationale for these choices is that quest chains are serially linked together and it is highly likely that all players will complete a number of quest chains during routine play, while class-specific quests involve gaining necessary skills for one's character and thus all players seek out such quests in order to progress in the game.

The quest chains were selected randomly, with one for every letter of the alphabet (based on the first non-article word in title). This resulted in 22 quest chains (with none for the letters $\mathrm{J}, \mathrm{Q}, \mathrm{X}$, or Z) comprising 178 individual quests and totaling 18,538 words. For class-specific quests, twenty quests were collected per class, with the exception of the Death Knight class (a hero class that can only be played at higher levels), for which five were included. This resulted in 185 individual quests comprising a total of 18,318 words. Player level was taken into account. There were more class-specific quests at the lower levels and this resulted in a distribution of four quests for each of the following level bands: 0-5, 6-10, 11-30, 31-50, and 50-85. All of the quest texts were obtained from wowwiki.com ${ }^{3}$. See Table 2 for an overview.

\subsection{Results and discussion: Quest texts}

The analysis of the two corpora of quest texts revealed that they are closely comparable for all measures used (see Table 3 for an overview of the linguistic analyses). This suggests that all the quest texts, regardless of being part of a chain or being class-specific, are similar in terms of readability and complexity.

The CLI readability measure suggests that both text samples are ranked as appropriate for 7th and 8th US grade level students, which is middle school level. This indicates that quest texts are suitable for children between the ages of twelve and fourteen. Contrasting somewhat with the readability measure, the LS, measuring the ratio of sophisticated lexical word types, was greater than .60 for both texts, which indicates that many of the lexical items appearing in the quest texts are lower-frequency and potentially more difficult or sophisticated words. The lexical diversity for both texts

3 http://www.wowwiki.com/Category:Quest_chains and http://www.wowwiki.com/Category: Quests_by_class 
Table 2 Overview of the collection of quests

\begin{tabular}{lll}
\hline \hline Quest type & Number of quests & Number of words \\
\hline \hline Quest chains & 178 & 18,538 \\
Class-specific & 185 & 18,318 \\
\hline \hline
\end{tabular}

Table 3 Overview of results of the linguistic complexity analysis of quest texts

\begin{tabular}{lllll}
\hline \hline Text sample & CLI & LS & MSTTR & D-Level \\
\hline \hline Quest chains & 7.0 & .64 & .78 & 4.4 \\
Class-specific quests & 7.8 & .66 & .78 & 4.4 \\
\hline \hline
\end{tabular}

was also high, with the MSTTR analysis showing .78 (1.0 is the maximum score for this measure, which would mean that all words in all 50-word text segments were unique). This indicates that the quest texts show a high proportion of unique (non-repeated) word types per 50-word sample. Finally, the D-Level scale indicates a mean score of 4.4, which reveals the presence of complex syntactic structures that include a variety of conjoined, relative clause, and comparative constructions.

To sum up, the analysis of the quest texts revealed that for all measures used, these two corpora of texts are lexically and syntactically comparable. Furthermore, quest texts show a high degree of lexical sophistication, lexical diversity, and syntactic complexity. However, the readability level as measured by CLI was quite modest, a finding that contrasts with the lexical and syntactic complexity measures. For this reason, we looked more closely at the output of the D-Level analysis. As discussed above, this syntactic complexity measure assigns individual sentences to one of eight developmental levels, as described in Table 4.

The mean D-Level for all sentences in both text samples is 4.4. In addition to providing a mean score, the D-Level analyzer categorizes sentences and thus allows for an examination of the distribution of sentence types within a sample. This analysis shows a very interesting pattern, namely that there are high numbers of both the simplest and most complex sentence types. This data is presented in Table 5.

Graphically representing the distribution of D-Level sentence types shows a rightskewed U-shape pattern, as depicted in Figure 4.

As was illustrated in Table 5, the proportion of sentences for both the d-0 level and the d-7 level are high, showing a strong polarisation between simple and difficult sentences. This indicates that there is considerable variability in sentence complexity levels within the texts, with the most complex level of sentences (d-7) occurring with greatest frequency. This demonstrates that in terms of syntactic complexity, mean scores present a homogenizing view of the actual data as a result of internal variability. In Table 6 , specific examples of the d- 0 and d- 7 sentences are provided. In the case of the d-7 sentences, a linguistic annotation indicates the specific constructions that are present. 
Table 4 Convington et al.'s (2006) revised D-Level scale

\begin{tabular}{|c|c|c|}
\hline Level & Description & Example \\
\hline \multirow[t]{3}{*}{0} & Simple sentences, including questions & John cried. \\
\hline & $\begin{array}{l}\text { Sentences with auxiliaries and semi- } \\
\text { auxiliaries }\end{array}$ & This has solved it. \\
\hline & Simple elliptical (incomplete) sentences & John did. \\
\hline 1 & $\begin{array}{l}\text { Infinitive or -ing complement with same } \\
\text { subject as main clause }\end{array}$ & Try to smile. \\
\hline \multirow[t]{3}{*}{2} & $\begin{array}{l}\text { Conjoined noun phrases in subject } \\
\text { position }\end{array}$ & John and Mary left. \\
\hline & $\begin{array}{l}\text { Sentences conjoined with a coordinating } \\
\text { conjunction }\end{array}$ & I came early but Peter arrived late. \\
\hline & $\begin{array}{l}\text { Conjoined verbal, adjectival or adverbial } \\
\text { constructions }\end{array}$ & He sang and jumped. \\
\hline \multirow[t]{5}{*}{3} & $\begin{array}{l}\text { Relative or appositional clause } \\
\text { modifying object of main verb }\end{array}$ & John scolded the boy who stole his bicycle. \\
\hline & Nominalization in object position & I understand his rejection of the offer. \\
\hline & Finite clause as object of main verb & John knew that Mary was angry. \\
\hline & Subject extraposition & It was hard for John to tell Mary. \\
\hline & Raising & John seems to Mary to be happy. \\
\hline \multirow[t]{2}{*}{4} & $\begin{array}{l}\text { Nonfinite complement with its own } \\
\text { understood subject }\end{array}$ & I saw him walking away. \\
\hline & Comparative with object of comparison & John is older than Mary. \\
\hline \multirow[t]{2}{*}{5} & $\begin{array}{l}\text { Sentences joined by a subordinating } \\
\text { conjunction }\end{array}$ & They won't play if it rains. \\
\hline & Nonfinite clauses in adjunct position & Having tried both, I prefer the second one. \\
\hline \multirow[t]{3}{*}{6} & $\begin{array}{l}\text { Relative or appositional clause } \\
\text { modifying subject of main verb }\end{array}$ & The man who cleans the room left early. \\
\hline & $\begin{array}{l}\text { Embedded clause serving as subject of } \\
\text { main verb }\end{array}$ & $\begin{array}{l}\text { For John to have left Mary was } \\
\text { surprising. }\end{array}$ \\
\hline & $\begin{array}{l}\text { Nominalization serving as subject of } \\
\text { main verb }\end{array}$ & His rejection of the offer was unexpected. \\
\hline 7 & More than one structure from Levels 1-6 & $\begin{array}{l}\text { John decided to leave Mary when he } \\
\text { heard that she was seeing Mark. }\end{array}$ \\
\hline
\end{tabular}

Table 5 D-Levels of the quest texts

\begin{tabular}{lcccccccc}
\hline \hline Text sample & $\mathrm{d}-0$ & $\mathrm{~d}-1$ & $\mathrm{~d}-2$ & $\mathrm{~d}-3$ & $\mathrm{~d}-4$ & $\mathrm{~d}-5$ & $\mathrm{~d}-6$ & $\mathrm{~d}-7$ \\
\hline \hline Quest chains & 313 & 18 & 68 & 64 & 26 & 61 & 16 & 628 \\
Class-specific quests & 312 & 14 & 87 & 63 & 32 & 48 & 11 & 651 \\
\hline \hline
\end{tabular}

A qualitative examination of the d-7 sentences illustrates the lexical and syntactic complexity that confront players on a frequent basis. Triangulating among these various measures of readability, lexical sophistication, and syntactic complexity with the D-Level scale, we conclude that as far as the quest texts are concerned, Wo $W$ presents to players an environment that includes a substantial volume of highly complex linguistic input. 

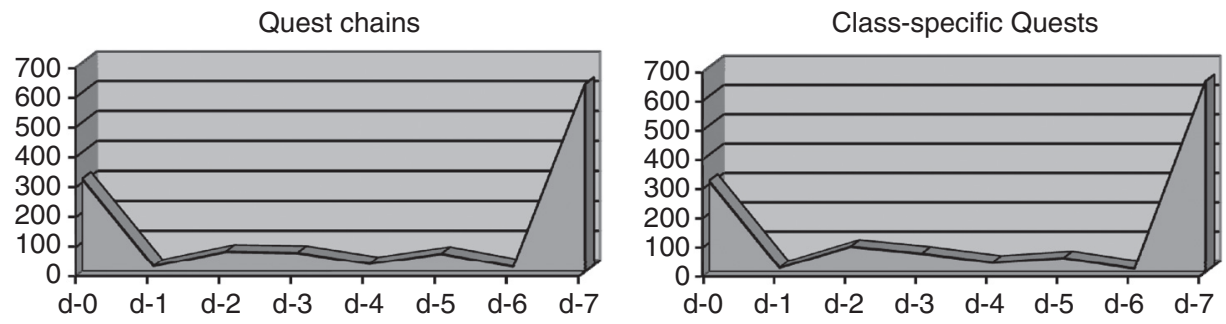

Fig. 4. D-Levels of the quest texts

Table 6 Examples of the most simple (d-0) and complex sentences $(d-7)$ in the quest text samples

\begin{tabular}{|c|c|c|}
\hline Text sample & $\mathrm{d}-0$ & d-7 (with description of syntactic structures present) \\
\hline \multirow[t]{3}{*}{ Quest chains } & 1. Hurry! & $\begin{array}{l}\text { Their beliefs are similar to ours and so killing them is } \\
\text { somewhat distasteful, but if they lack the strength to } \\
\text { resist us, then they do not deserve their lives. } \\
\text { [sentences joined by subordinating and coordinating } \\
\text { conjunctions] }\end{array}$ \\
\hline & 2. Trust me! & $\begin{array}{l}\text { The sprites and satyrs that have taken up residence in } \\
\text { the area feed upon the magical energies of the area, } \\
\text { their powers growing from continued exposure. } \\
\text { [conjoined noun phrase in subject position; relative } \\
\text { clause modifying subject of main verb; nonfinite } \\
\text { clause in adjunct position] }\end{array}$ \\
\hline & $\begin{array}{l}\text { 3. The keg frizzles } \\
\text { slightly }\end{array}$ & $\begin{array}{l}\text { My hatred for the elves burns, but I do not wish ill } \\
\text { upon their children, so we must police our own. } \\
\text { [nominalization in subject position; sentences joined } \\
\text { by coordinating and subordinating conjunctions] }\end{array}$ \\
\hline \multirow[t]{3}{*}{$\begin{array}{l}\text { Class-specific } \\
\text { quests }\end{array}$} & 1. Be warned! & $\begin{array}{l}\text { You can manage the flows of magic, yes, but being a } \\
\text { warlock is much more than that. [coordinated } \\
\text { sentence; comparative with object of comparison] }\end{array}$ \\
\hline & 2. Kill them! & $\begin{array}{l}\text { Considering the power you already wield as a warlock, } \\
\text { I can only assume you know the satyrs of Felwood } \\
\text { carry this felcloth. [nonfinite clause in adjunct } \\
\text { position; finite clause of object of main verb] }\end{array}$ \\
\hline & 3. Remember that! & $\begin{array}{l}\text { A Doomguard is a cunning and lethal adversary and } \\
\text { will seek to destroy you as you begin the ritual of } \\
\text { imprisonment. [conjoined adjectival and verb } \\
\text { constructions; infinitive complement; sentences } \\
\text { joined by subordinating conjunction] }\end{array}$ \\
\hline
\end{tabular}

\section{Linguistic complexity analysis of external website text samples}

\subsection{Description of corpora}

Based on the results from the questionnaire and follow-up interviews, it became clear that several external sources were frequently read by almost all respondents. 
Table 7 Overview of the collection of text samples from external sources

\begin{tabular}{lll}
\hline \hline External source & Type of information & Number of words \\
\hline \hline wowhead.com & Quest help & 16,7406 \\
& Items & 11,662 \\
wowwiki.com & Lore & 21,187 \\
& Class information & 32,959 \\
elitistjerks.com & Strategy & 14,682 \\
\hline \hline
\end{tabular}

Text samples were collected from these sites in order to carry out linguistic complexity analyses on their contents. The sites included:

- http://www.wowhead.com: Topics include strategy for completing quests and information on items in the game (e.g., armor, weapons, etc.).

- http://www.wowwiki.com/Portal:Main: Lore and mythology of the WoW universe; information related to different classes (or types) of online character.

- http://elitistjerks.com/: Game related strategy and general topics related to WoW.

As indicated by the questionnaire and interview data, wowhead.com is used by nearly all respondents to look up information about items in the game and for strategy to successfully complete quests. Two text samples were collected from this site, one focused on item information and the second on quest strategy. Wowwiki.com is used mainly to learn about $W o W$ lore and information about the different player classes. Again, two text samples were assembled for each of these themes. Elitistjerks.com is used mainly for in-depth discussion of game strategy. The specifics of these corpora are described in Table 7.

\subsection{Results and discussion}

Results of the linguistic complexity analysis of the most visited external resources are presented in Table 8 . The readability measures demonstrate that there is a small difference between the wowhead items and quest text samples. The former shows a CLI of 6.7 and the latter a CLI of 7.6, suggesting that the texts are suitable for children between the ages of twelve and fourteen. The other samples are ranked as more complex and range between 9th to 11th US grade levels, which correlates with the readability level of young people between the ages of fourteen and seventeen. There is, however, a high degree of lexical sophistication with the ratio of sophisticated lexical word types greater than .60 for all texts, and a high degree of lexical diversity for all texts, with the MSTTR varying between .76 and .79 . The D-Level analysis of syntactic complexity registered at the extreme high end of the scale, with mean scores greater than 6 for all corpora with the exception of the wowhead quest sample.

As was the case with the quest texts analysed earlier in section 5, the mean score readability outcome for the external sites runs contrary to the syntactic and linguistic complexity measure outcomes. However, further examination of the distribution of sentences across the D-Level categories shows that the game-external website texts are comprised of predominantly $\mathrm{d}-7$ sentence types, with the single exception 
Table 8 Overview results linguistic complexity analysis of external websites

\begin{tabular}{lrccc}
\hline \hline Text sample & CLI & LS & MSTTR & D-Level \\
\hline \hline wowhead: items & 6.7 & .61 & .78 & 6.3 \\
wowhead: quests & 7.6 & .60 & .77 & 3.6 \\
wowwiki: class info & 10.8 & .70 & .78 & 6.6 \\
wowwiki: lore & 11.1 & .70 & .76 & 6.4 \\
elitistjerks: strategy & 9.1 & .63 & .79 & 6.1 \\
\hline \hline
\end{tabular}

Table 9 D-Levels of the external site text samples

\begin{tabular}{lrllllllr}
\hline \hline Text sample & d-0 & d-1 & d-2 & d-3 & d-4 & d-5 & d-6 & d-7 \\
\hline \hline wowhead: items & 68 & 0 & 16 & 18 & 4 & 15 & 4 & 857 \\
wowhead: quests & 365 & 6 & 22 & 28 & 6 & 35 & 5 & 380 \\
wowwiki: class info & 61 & 4 & 17 & 16 & 6 & 17 & 3 & 1671 \\
wowwiki: lore & 59 & 3 & 25 & 9 & 3 & 24 & 1 & 966 \\
elitistjerks: strategy & 120 & 2 & 12 & 12 & 6 & 22 & 1 & 910 \\
\hline \hline
\end{tabular}
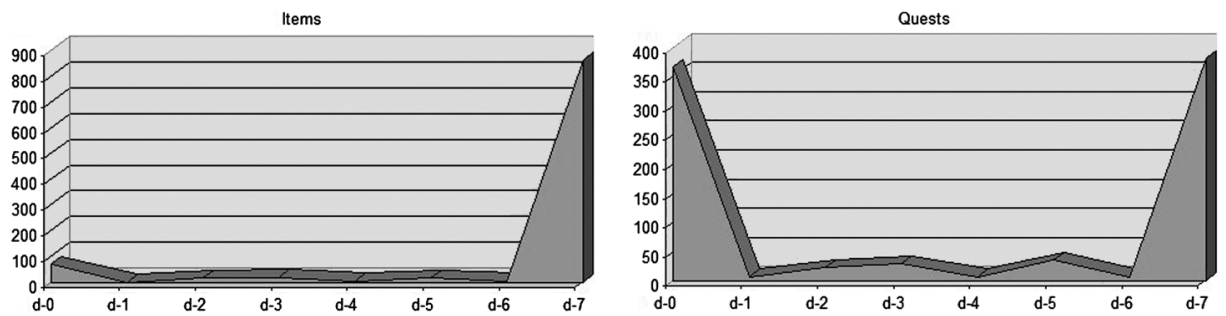

Fig. 5. D-Levels of the text samples from wowhead

of wowhead's quest texts, which were characterized by a symmetrical distribution of d-0 and d-7 sentences (see Table 9).

Represented graphically, wowhead's items text sample shows a right-skewed peak at the d-7 level, whereas a symmetrical U-shape pattern is revealed for the wowhead quest text sample (see Figure 5).

The strong polarisation in the quest text sample indicates internal variability in complexity level (see Table 10 for examples). It is relevant to note that the wowhead quest text corpus comprises player-to-player texts, written by gaming enthusiasts, which we will further discuss below.

Figures 6 and 7 illustrate that the text samples from wowwiki and elitistjerk are similar to the wowhead items sample in that they show a right-skewed peak at the d-7 level.

The right-skewed data in Figures 6 and 7 indicate that these texts are more uniformly complex in terms of the distribution of sentences. The wowhead quests 
Table 10 Examples of the most simple $(d-0)$ and complex sentences $(d-7)$ in wowhead's quest text sample

\section{Text}

d-7 (with description of syntactic structures present)

1. Do we have a deal?

2. Give me the contract.

3
Ignoring raid activity, when $\mathrm{BC}$ was released the story became that kazzak was stranded and looking for a way to reopen the dark portal, and when he succeeded he went back through it. [nonfinite clause in adjunct position; sentences joined by subordinating conjunction; finite clauses as object of main verb; conjoined verbal construction]

Bring a raid with you when you return with the required items to Demitrian, because he will promptly summon Thunderaan, who is not the least bit happy that he was locked away for so long. [sentences joined by subordinating conjunction; relative clause modifying object of main verb]

3. I must have it. To minimise your chance at getting ganked if you are not already flagged when desecrating a fire, you can start summoning your mount before clicking "Complete Quest". [nonfinite clause in adjunct position; sentences joined by subordinating conjunction; infinitive -ing complement with same subject as main clause]
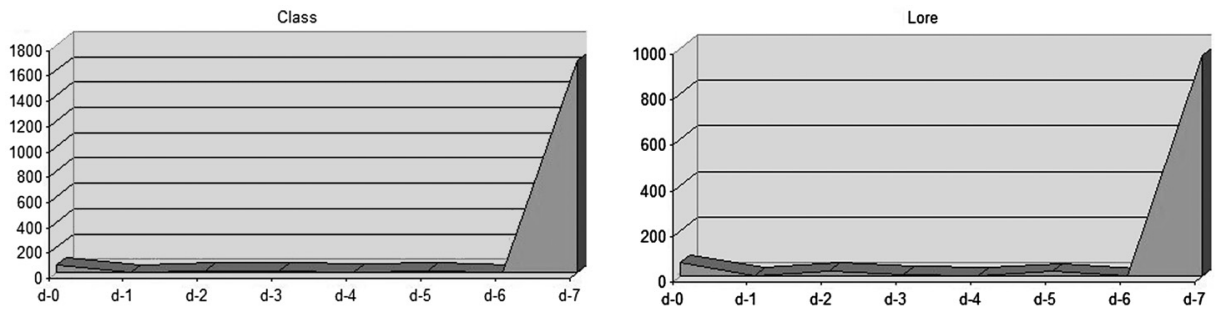

Fig. 6. D-Levels of the text samples from wowwiki

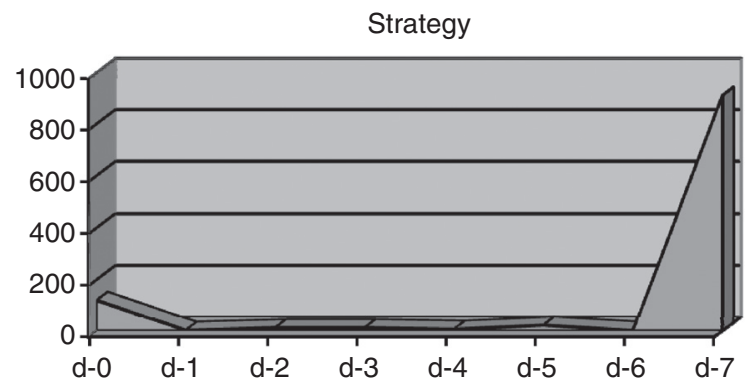

Fig. 7. D-Levels of the text sample from elitistjerks

text corpus (Figure 5), in contrast, is similar to the in-game quest text corpora (see Figure 4) as it shows a strong polarisation between simple and difficult sentences, with the most complex sentences (d-7) occurring at approximately the same 
Table 11 Examples of the conversational simple sentences in the interpersonal text samples

Texts illustrating phatic and interactive discourse features

Quest chains

Ready to go, $<$ name $>$ ?

Hey there! You look like you can handle your brew. But can you handle your brew mug?

Class-specific quests

I want to teach you a basic healing technique, $<$ name $>$.

Your garment is ready!

Wowhead: quests

God I am bored to be finding all of these!

Can I desecrate a fire after someone from the opposite side reignites it or can I only do it once?

frequency as very simple sentences, a fact that is not apparent when one only looks at the mean D-Level scores.

The difference in the distribution of complex sentences between the game-generated quest texts and wowhead quest text sample on the one hand (Figures 4 and 5), and the wowhead item text sample and the text samples from wowwiki and elitistjerks on the other (Figures 6 and 7), is probably due to differences in genre - that the former are interpersonally oriented texts (e.g., many sentences using second person address forms) while the latter are cases of expository or informational texts. Genre theorists Knapp and Watkins (2005) note that third person texts are stylistically more objective in tone while the use of personal pronouns tends to dialogically engage the reader (see also Kamberelis, 1999). In the case of the in-game quest texts, they are written as if the NPC and the player are talking to each other, and thus are conversational in genre. Similarly, the player-authored wowhead quest text strategy commentaries are posted on an interactive discussion forum and are written as dialogical discourse with expectations for response and debate. Additionally, these texts show high levels of phatic communication, indicating that interpersonally oriented and community building communication is interwoven with the conveyance of information. The presence of clause level interactive discourse features is visible in the d- 0 and d-7 sentence types shown in Table 9. Corresponding examples of dialogically oriented discourse from the game-generated quest corpora and the player authored wowhead quest strategy forums are displayed in Table 11.

\section{Discussion}

For both the Dutch and the American gamers, external websites associated with $W o W$ were used by everyone and with great frequency. WoW players look up information on the background story of the game, how to complete certain assignments, how to optimize their characters, for assistance with strategy, and much more. All of the ten interviewees reported that they used external websites before, during, and after gaming sessions. Based on these consistent data, we propose that, for this sample of players, external websites function as keystone species within $W_{o} W^{\prime}$ s broader semiotic ecology. In terms of the generalizability of the questionnaire and interview findings, there are limitations to this research, namely the relatively modest 
subject pool of sixty-four participants restricted to two geographical regions - the Netherlands and the United States. Additionally, the respondents, on average, were highly skilled gamers whose experience may not represent that of novices. The applicability of the questionnaire results to other populations, therefore, should be understood as tentative.

The analysis of the text samples from the external websites revealed a high degree of lexical sophistication, lexical diversity, syntactic complexity, and based on the D-level scores, a significant proportion of structurally complex sentences. To summarize, the most popular $W o W$-related external websites are relatively rich in lexical sophistication and diversity, include multiple genres - from informational and expository prose to interactive "I-you" and conversational text types, and illustrate a high proportion of both complex syntactic structures as well as interactive and interpersonally engaged discourse.

It also bears noting that related research focusing on the cognitive content of strategy and game-play websites shows that these texts are rhetorically and logically complex. To take one example, Steinkuehler and Duncan (2008) have argued that $W o W$ discussion forums foster "scientific habits of mind." Analyses of nearly $2,000 \mathrm{WoW}$-related forum posts revealed that $86 \%$ of the entries displayed "social knowledge construction" rather than "social banter" alone, that $65 \%$ treated knowledge "as an open-ended process of evaluation and argument", that more than half of the posts included evidence of systems-based reasoning, and that $10 \%$ showed scientifically precise model-based reasoning (Steinkuehler \& Duncan, 2008: 539). The complexity analyses presented here were intentionally and narrowly limited to the linguistic assessment of in-game and out-of-game high frequency texts that players would experience as a part of their regular gaming activity. As for the cognitive and reasoning content of specifically game-external website resources, and in contradistinction to the often negative public perceptions of gamers and gaming culture, the ethnographic and analytic research of Steinkuehler and Duncan (2008), Gee (2007), Squire (2008b), and Collins and Halverson (2009), among others, has demonstrated that MMOs, and $W_{o} W$ in particular, constitute semiotic ecologies that serve as an arena for recreation as well as for intellectually challenging and scientifically informed discourse and forms of play.

\section{Conclusion}

According to usage-based research on language development, trajectories of language learning stem from exposure to meaningful uses of language and opportunities for communicative engagement. Tomasello (2000), for example, describes the bottom-up process of language acquisition this way: "All linguistic knowledge ... derives in the first instance from the comprehension and production of specific utterances on specific occasions of use" (op. cit.: 237-238). In essence, exposure to language and opportunities for situated communicative activity are massively influential developmental forces. In the modern era, certainly a case can be made that for many individuals, online interaction serves as a primary context for language socialization and engagement with a wide range of written genres, including those constituting the complex and distributed semiotic ecologies of gaming worlds. 
Within second language development research, numerous studies have described the importance of reading and frequency of input for the acquisition of linguistic structures, vocabulary, and genre-specific text conventions (e.g., Ellis, 2002; Hyland, 2002; Nation, 2004; Pigada \& Schmitt, 2006). While there exist disagreements concerning developmental trajectories as they relate to the volume of exposure to, and quality of, linguistic environments (e.g., debates between DeKeyser \& Larson-Hall (2005) and Flege (2009) and between Ellis (2002) and Gass \& Mackey (2002)), there is no disagreement about the essential need for high levels of engagement with the semiotic systems and signifying practices one wishes to learn. This said, the amount of exposure to and interaction in the L2 will strongly depend on what the player wishes to do and to achieve in the game. To more fully understand the real-time process of actual people doing actual things with and through language, a more complex, non-causal and nuanced approach may be warranted. Espousing such a view, and taking a dynamic systems theory perspective, Verspoor, de Bot and Lowie (2009) noted that linguistic 'input' is not simply taken in or passively absorbed, but interacted with by readers/listeners. This results in variable processes where the 'same' input, a quest text or $W o W$ strategy website for example, may be read or acted upon in different ways depending upon a player's immediate needs and goals as well as his/her evolving history of game play. In this sense, the reading of texts and the associated action sequences of players form complex and adaptive systems that reorganize themselves based on the contingencies of the immediate goal-directed activity at hand.

This research has sought to better understand which texts are most important to players and to submit these player-designated high frequency texts to thorough linguistic analysis. The lexical and syntactic complexity of $W o W$-related texts was shown to be sophisticated, complex, and with direct and event-driven use-value to players. The multiple genres and 'just-in-time' information presented by gamegenerated and player produced texts serve the immediate and situated needs of MMO players. In essence, these texts are attended to because they are highly relevant to the actions, decisions, and problem-solving at hand. Taking an ecological perspective, van Lier (2004) defines the term 'affordances' as a relationship between an organism and its environment that "signals an opportunity for or inhibition of action" (op. cit.: 4; see also Bateson, 1972). In application to the reading of quest, strategy, lore, and informational affordances relating to $W_{o} W$, these texts can be seen as "the raw materials out of which signs grow, and from which language emerges" (van Lier, 2004: 63). As Gee (2007) suggests, texts, and more generally communication, are best comprehended and internalized when they are functionally and lucidly tied to specific practices, a formulation that accurately describes the interplay of $W o W$-associated texts and the activity of MMO game play. Especially in combination with player-to-player communication, which was beyond the scope of this article to discuss, $W_{0} W$ would seem to present a diverse and linguistically complex social-semiotic environment for L2 learners of English. Based on player reports (Thorne, 2008, 2010), and the authors' personal MMO game play experiences together with the findings of other articles in this special issue of $\operatorname{ReCALL}$, presumably the same would hold true for the available versions of $W o W$ in other languages. 


\section{References}

Bateson, G. (1972) Steps to an ecology of mind. Chicago: University of Chicago Press.

Brown, J. S. and Thomas, D. (2008) The gamer disposition. Harvard Business Review Blogs. http://blogs.hbr.org/cs/2008/02/the_gamer_disposition.html

Carr, N. (2010) The shallows: What the Internet is doing to our brains. New York: W.W. Norton \& Company.

Coleman, M. and Liau, T. L. (1975) A computer readability formula designed for machine scoring. Journal of Applied Psychology, 60: 283-284.

Collins, A. and Halverson, R. (2009) Rethinking education in the age of technology. New York: Teachers College Columbia University.

Covington, M. A., He, C., Brown, C., Naçi, L. and Brown, J. (2006) How complex is that sentence? A proposed revision of the Rosenberg and Abbeduto D-Level scale. CASPR Research Report 2006-01. Athens, GA: The University of Georgia, Artificial Intelligence Center.

Crockett, L., Schulenberg, J. and Petersen, A. (1987) Congruence between objective and selfreport data in a sample of young adults. Journal of Adolescent Research, 2(4): 383-392.

Davison, A. and Kantor, R. N. (1982) On the failure of readability formulas to define readable texts: A case study from adaptations. Reading Research Quarterly, 17: 187-209.

DeHaan, J. (2005) Learning language through video games: A theoretical framework, an evaluation of game genres and questions for future research. In: Schaffer, S. P. and Price, M. L. (eds.), Interactive convergence: critical issues in multimedia. Oxford: Inter-Disciplinary Press, 229-239.

DeKeyser, R. and Larson Hall, J. (2005) What does the critical period really mean?. In: Kroll, J. and De Groot, A. (eds.), Handbook of bilingualism: Psycholinguistic approaches. Oxford: Oxford University Press, 88-108.

Ellis, N. (2002) Reflections on frequency effects in language processing. Studies in Second Language Acquisition, 24: 297-339.

Ellis, N. and Collins, L. (2009) Input and Second Language Acquisition: The roles of frequency, form and function. Introduction to the special issue. Modern Language Journal, 93: 329-335.

Ellis, N. and Ferreira-Junior, F. (2009) Construction learning as a function of frequency, frequency distribution, and function. Modern Language Journal, 93: 370-385.

Flege, J. (2009) Give input a chance!. In: Piske, T. and Young-Scholten, M. (eds.), Input matters in SLA. Bristol: Multilingual Matters, 175-190.

Gass, S. and Mackey, A. (2002) Frequency effects and second language acquisition. Studies in Second Language Acquisition, 24: 249-260.

Gee, J. P. (2003) What video games have to teach us about learning and literacy. New York: Palgrave Macmillan.

Gee, J. P. (2005) Semiotic social spaces and affinity spaces: From the age of mythology to today's schools. In: Barton, D. and Tusting, K. (eds.), Beyond communities of practice: Language, power, and social context. Cambridge: Cambridge University Press, 214-232.

Gee, J. (2007) Good video games and good learning. New York: Peter Lang.

Grimes, S. and Feenberg, A. (2009) Rationalizing play: A critical theory of digital gaming. Information Society, 25: 105-118.

Hart, B. and Risley, T. (1995) Meaningful differences in the everyday experience of young American children. Baltimore: Brookes Publishing.

Hyland, K. (2002) Genre: Language, context and literacy. Annual Review of Applied Linguistics, 22: $113-135$.

Johnson, W. (1944) Studies in language behavior: I. A program of research. Psychological Monographs, 56: 1-15. 
Kamberelis, G. (1999) Genre, development and learning: Children writing stories, science and poems. Research in the teaching of English, 3: 403-460.

Knapp, P. and Watkins, M. (2005) Genre, text, grammar: Technologies for teaching and assessing writing. New South Wales: University of New South Wales Press Ltd.

Lee, J. and Hoadley, C. (2007) Leveraging identity to make learning fun: Possible selves and experiential learning in massively multiplayer online games (MMOGs). Innovate, 3(6). http://innovateonline.info/index.php?view $=$ article $\%$ id $=348$

Lu, X. (2009) Automatic measurement of syntactic complexity in child language acquisition. International Journal of Corpus Linguistics, 14(1): 3-28.

$\mathrm{Lu}, \mathrm{X}$. (in press) The relationship of lexical richness to the quality of ESL learners' oral narratives. Modern Language Journal.

MacWhinney, B. (2000) The CHILDES project: Tools for analyzing talk. Mahwah, NJ: Lawrence Erlbaum Associates.

Nardi, B. and Kallinikos, J. (2010) Technology, agency, and community: The case of modding in World of Warcraft. In: Holmström, J., Wiberg, M. and Lund, A. (eds.), Industrial informatics design, use and innovation. IGI Global, 174-186.

Nardi, B., Ly, S. and Harris, J. (2007) Learning conversations in World of Warcraft. The proceedings of the 2007 Hawaii International Conference on Systems Science. New York: IEEE Press, 1-10.

Nation, I. S. P. (2004) Vocabulary learning and intensive reading. EA Journal, 21(2): 20-29.

Ortega, L. (2003) Syntactic complexity measures and their relationship to L2 proficiency: A research synthesis of college-level L2 writing. Applied Linguistics, 19(2): 492-518.

Peterson, M. (2010) Computerized games and simulations in computer-assisted language learning: A meta-analysis of research. Simulation \& Gaming, 41(1): 72-93.

Pigada, M. and Schmitt, N. (2006) Vocabulary acquisition from extensive reading: A case study. Reading in a Foreign Language, 18(1): 1-28.

Piirainen-Marsh, A. and Tainio, L. (2009) Other repetition as a resource for participation in the activity of playing a video game. Modern Language Journal, 93: 153-169.

Purushotma, R., Thorne, S. L., and Wheatley, J. (2009) Language learning and video games. Paper produced for the Open Language \& Learning Games Project, Massachusetts Institute of Technology, funded by the William and Flora Hewlett Foundation. http://lingualgames. wordpress.com/article/10-key-principles-for-designing-video-27mkxqba7b13d-2/

Reinders, H. (ed.) (2012) Digital games in language learning and teaching. Basingstoke: Palgrave Macmillan.

Reppen, R. and Ide, N. (2004) The American National Corpus: Overall goals and the first release. Journal of English Linguistics, 32: 105-113.

Rosenberg, S. and Abbeduto, L. (1987) Indicators of linguistic competence in the peer group conversational behavior of mildly retarded adults. Applied Psycholinguistics, 8: 19-32.

Squire, K. (2008a) Video-game literacy: A literacy of expertise. In: Coiro, J., Knobel, M., Lankshear, C. and Leu, D. (eds.), Handbook of research on new literacies. Mahwah, NJ: Erlbaum, 639-673.

Squire, K. (2008b) Open-ended video games: A model for developing learning for the interactive age. In: Salen, K. (ed.), The ecology of games: Connecting youth, games, and learning. Cambridge, MA: The MIT Press, 167-198.

Steinfield, C., Ellison, N. and Lampe, C. (2008) Social capital, self-esteem, and use of online social network sites: A longitudinal analysis. Journal of Applied Developmental Psychology, 29: 434 445.

Steinkuehler, C. (2008) Cognition and literacy in massively multiplayer online games. In: Coiro, J., Knobel, M., Lankshear, C. and Leu, D. (eds.), Handbook of research on new literacies. Mahwah, NJ: Erlbaum, 611-634. 
Steinkuehler, C. and Duncan, S. (2008) Scientific habits of mind in virtual worlds. Journal of Science Education \& Technology, 17: 530-543.

Sykes, J., Reinhardt, J. and Thorne, S. L. (2010) Multiplayer digital games as sites for research and practice. In: Hult, F. (ed.), Directions and prospects for educational linguistics. New York: Springer, $117-136$.

Thomas, D. and Brown, J. S. (2009) Why virtual worlds can matter. International Journal of Learning and Media, 1(1): 37-49.

Thorne, S. L. (2008) Transcultural communication in open Internet environments and massively multiplayer online games. In: Magnan, S. (ed.), Mediating discourse online. Amsterdam: John Benjamins, 305-327.

Thorne, S. L. (2010) The "intercultural turn" and language learning in the crucible of new media. In: Helm, F. and Guth, S. (eds.), Telecollaboration 2.0 for language and intercultural learning. Bern, Switzerland: Peter Lang, 139-164.

Thorne, S.L., Black, R. W. and Sykes, J. (2009) Second language use, socialization, and learning in Internet interest communities and online gaming. Modern Language Journal, 93: 802-821.

Thorne, S. L. and Fischer, I. (2012). Online gaming as sociable media. ALSIC [En ligne]: Apprentissage des Langues et Systémes d'Information et de Communication, 15(1), http://alsic.revues.org/2450; doi:10.4000/alsic.2450.

Tomasello, M. (2000) Do young children have adult syntactic competence? Cognition, 74: 209-253.

Turkle, S. (1995) Life on the screen: Identity in the age of the Internet. New York: Simon \& Schuster.

Turkle, S. (2011) Alone together: Why we expect more from technology and less from each other. New York: Basic Books.

van Lier, L. (2004) The ecology and semiotics of language learning: A sociocultural perspective. Boston: Kluwer.

Verspoor, M., de Bot, K. and Lowie, W. (2009) Input and second language development from a dynamic perspective. In: Piske, T. and Young-Scholten, M. (eds.), Input matters. Clevedon: Multilingual Matters, 62-80.

Zheng, D., Young, M., Wagner, M. and Brewer, R. (2009) Negotiation for action: English language learning in game-based virtual worlds. Modern Language Journal, 93: 489-511. 